\title{
Fourth metatarsal basis stress fracture after steroid use secondary to COVID-19
}

\author{
Enver Kılıç@, Olgun Bingöl(D), Atahan Durğal (D), Güzelali Özdemir (D) \\ Department of Orthopedics and Traumatology, Ankara City Hospital, Ankara, Turkey
}

Stress fractures are mostly seen in the tibia, fibula, navicular, and metatarsal bones in the lower extremities due to overuse injury. ${ }^{[1]}$ It is more common in athletes and military personnel. ${ }^{[2]}$ In the formation of stress fractures, there are intrinsic factors such as low bone density, hormonal balance, body composition, skeletal alignment, leg length inequality, muscle strength, nutritional reasons, and extrinsic factors such as shoe selection, activity intensity, activity frequency, and ground characteristics. ${ }^{[3]}$

At the time of writing this case report, the World Health Organization (WHO) has reported more than 170 million cases and more than 3.5 million deaths due to novel coronavirus disease 2019 (COVID-19) caused by severe acute respiratory syndrome-coronavirus 2 (SARS-CoV-2), which first appeared in Wuhan, China in December 2019 and later caused a pandemic. To date, many medical treatments have been attempted clinically for COVID-19 pneumonia and associated complications, and studies are still ongoing for an effective treatment. One of the drug groups used in the

Received: January 06, 2022

Accepted: January 14, 2022

Published online: February 10, 2022

Correspondence: Olgun Bingöl, MD. Ankara Şehir Hastanesi, Ortopedi ve Travmatoloji Kliniği, 06800 Çankaya, Ankara, Türkiye.

E-mail: olgunbingol@gmail.com

Doi: $10.52312 /$ jdrscr.2022.62

Citation: Kılıç E, Bingöl O, Durğal A, Özdemir G. Fourth metatarsal basis stress fracture after steroid use secondary to COVID-19. Jt Dis Relat Surg Case Rep 2022;1(2):59-62.

\section{ABSTRACT}

Stress fractures are mostly seen in the tibia, fibula, navicular, and metatarsal bones in the lower extremities due to overuse injury. A 27-year-old male patient, working as a surgical resident in a tertiary referral hospital, presented with pain on the right foot and difficulty in weight bearing and walking. His symptoms developed approximately a month after being diagnosed with novel coronavirus disease 2019 (COVID-19) and receiving systemic corticosteroid treatment. His history revealed weight gain and excessive working hours. He was diagnosed with stress fracture of the fourth metatarsal basis and treated conservatively. In conclusion, possible muscle/tendon, and bone pathologies and stress fractures secondary to systemic corticosteroid use and increased body mass index should be kept in mind, while evaluating the complaints of patients who have had COVID-19 and have a history of systemic steroid use in daily orthopedic practice, considering the side effects of steroids on the musculoskeletal system.

Keywords: Corticosteroids, COVID-19, metatarsal, stress fracture.

clinic due to COVID-19 pneumonia is corticosteroids, which were also used in the treatment of acute respiratory distress syndrome (ARDS) during the SARS pandemic that emerged in 2003. ${ }^{[4]}$

Herein, we present a case of stress fracture which can be associated systemic corticosteroid use for COVID-19 infection.

\section{CASE REPORT}

A 27-year-old male, working as a surgical resident in a tertiary referral hospital presented with pain on the right foot and difficulty in weight-bearing and walking. The patient had no known chronic disease or drug history. He had no previous surgery or previous fractures or stress fractures. However, the patient had bilateral flexible pes planus deformity.

While the patient was working at the hospital in March 2021, he developed symptoms of fever and weakness. He applied to the emergency service 

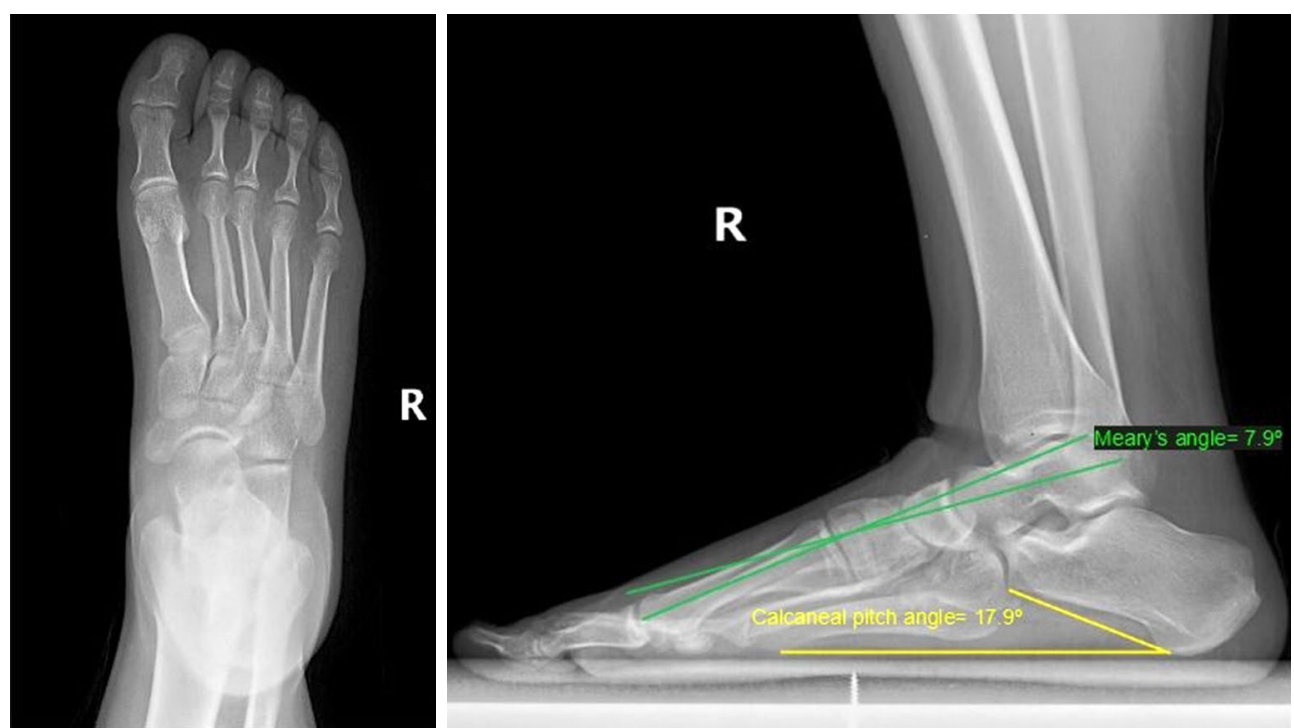

Figure 1. Anteroposterior and standing lateral X-rays of the right foot on the first admission. Standing lateral X-ray of the right foot showing the flexible pes planus of the right foot. Also, Meary's angle and calcaneal pitch angle on the lateral X-ray of the right foot.

three days later with the complaint of shortness of breath. After being diagnosed with COVID-19, he was hospitalized on the same day considering the severity of his symptoms. The patient was administered enoxaparin sodium $40 \mathrm{mg}$ b.i.d. for 12 days, dexamethasone $5 \mathrm{mg}$ once daily per oral for 10 days, favipiravir $600 \mathrm{mg}$ b.i.d. after loading $1600 \mathrm{mg}$ b.i.d. for five days, paracetamol $500 \mathrm{mg}$ b.i.d. intravenously. After 12 days, the patient recovered, there was no worsening of the disease, and he was discharged at the end of March 2021.
After discharge, the patient was quarantined for 15 days and, then, returned to work. After working for a while, the patient was admitted to the orthopedics outpatient clinic in April 2021 with complaints of foot pain and difficulty in weight bearing and walking for 20 days. Upon physical examination, the inspection was normal, there was no swelling, bruising or color change in the foot. On palpation, there was tenderness at the base of the fourth metatarsal on the dorsum of the foot. Foot and ankle joint ranges of motion were
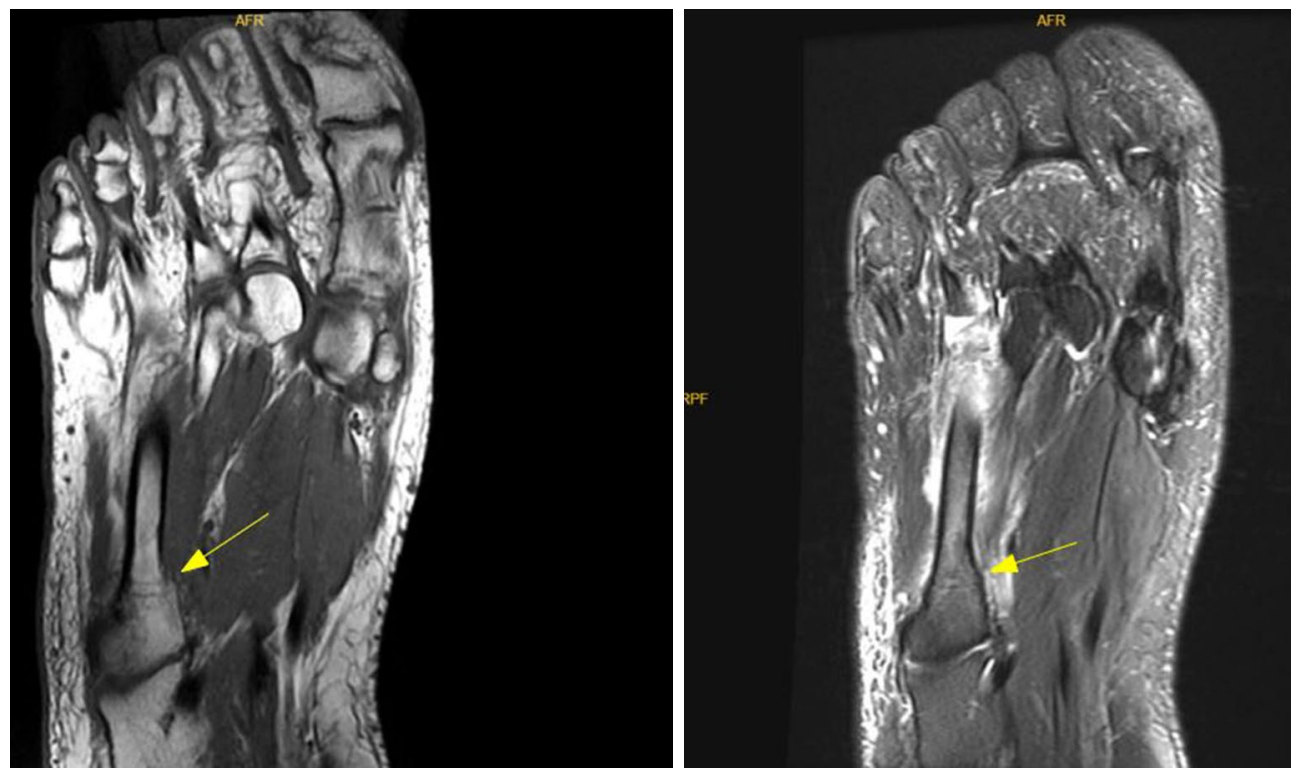

Figure 2. T1- and T2-weighted coronal plane magnetic resonance imaging scans of the right foot. T1-weighted coronal plane image is demonstrated on the left and T2-weighted image is on the right. Stress fracture is indicated by the yellow arrows. 

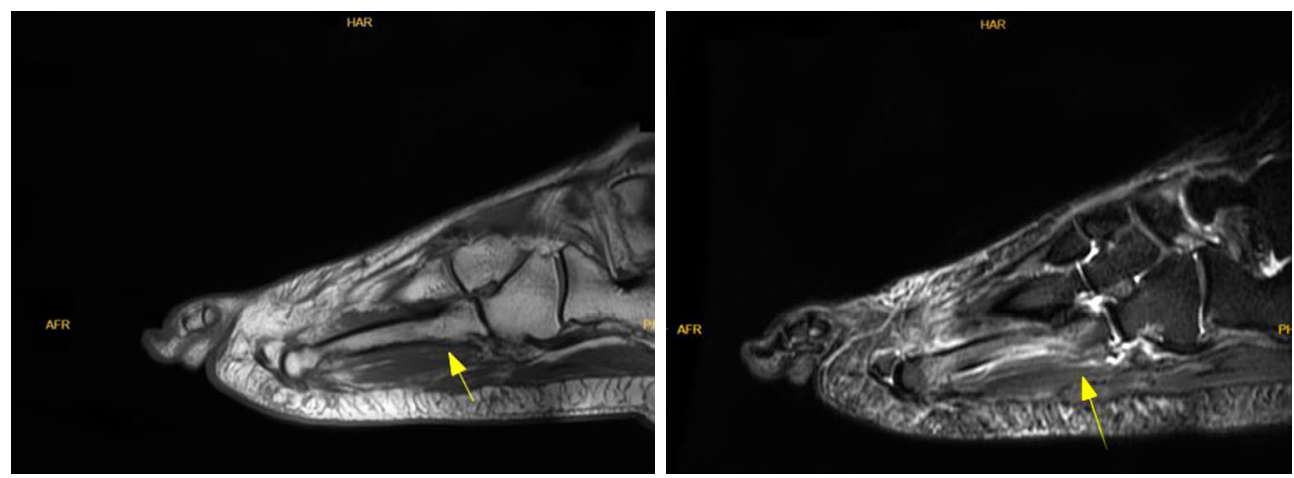

Figure 3. T1-weighted and STIR sequence sagittal plane MRI of the right foot. T1-weighted image on the right and STIR sequence on the left. Generalized edema is seen in the $4^{\text {th }}$ metatarsal of the foot on the STIR sequenced MRI. Stress fracture is indicated by the yellow arrows.

STIR: Short-TI inversion-recovery; MRI: Magnetic resonance imaging

evaluated completely. No pathology was found in the neurovascular examination. Direct radiographs of the foot and ankle were taken. On the radiographs, the patient was suspected to have a flexible pes planus, but no significant additional pathology was observed (Figure 1). With a meticulous inspection of the medical history of the patient, he was recently infected with COVID-19 and had a weight gain of 13 $\mathrm{kg}$. The patient's body mass index (BMI) increased from $28.1 \mathrm{~kg} / \mathrm{m}^{2}$ to $32.4 \mathrm{~kg} / \mathrm{m}^{2}$ over 45 days. In addition, a history of long working hours and long-standing and walking after discharge related to the working environment was taken from the patient. Then, the patient was suspected of having a stress fracture, and magnetic resonance imaging (MRI) of the foot was performed. The preliminary diagnosis was confirmed by the fissure line in the
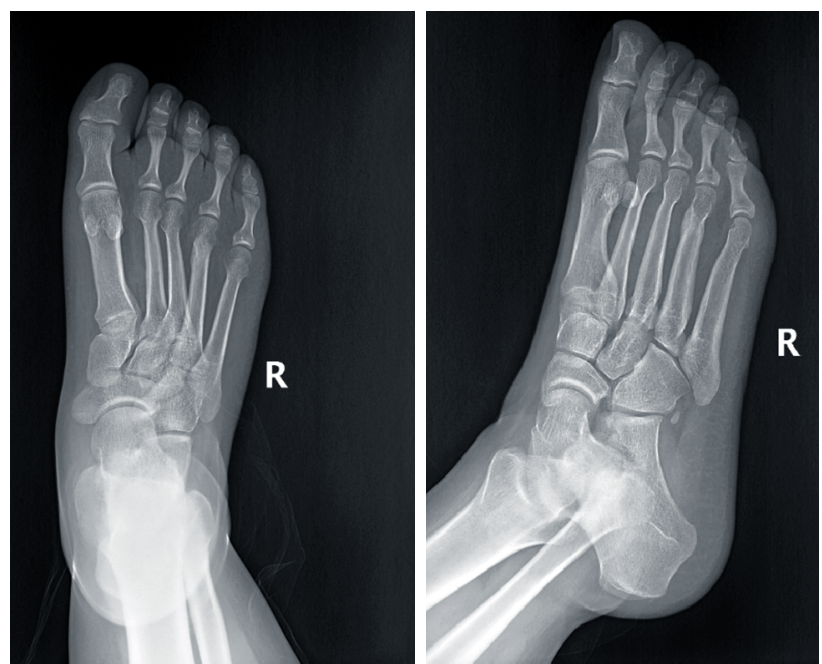

Figure 4. Oblique and anteroposterior views of the right foot at sixth week of follow-up.
$\mathrm{T} 1$ sequence at the base of the fourth metatarsal and generalized hyperintensity in the T2 images of the fourth metatarsal on MRI (Figures 2 and 3).

A short leg splint was applied and the patient was mobilized with a pair of crutches without any weight bearing. The patient was mobilized for six weeks without weight bearing and was followed on an outpatient basis. At the end of the sixth week, the splint was removed, and control radiographs were seen (Figure 4), and partial mobilization was initiated and followed for another three weeks. After the $\mathrm{X}$-rays showed signs of sclerosis and improvement at 10 weeks of follow-up, the patient was given full weight bearing and the crutches were released. The pain of the patient disappeared by standing on foot and walking (Figure 5). He was followed by applying shoes and activity modifications.
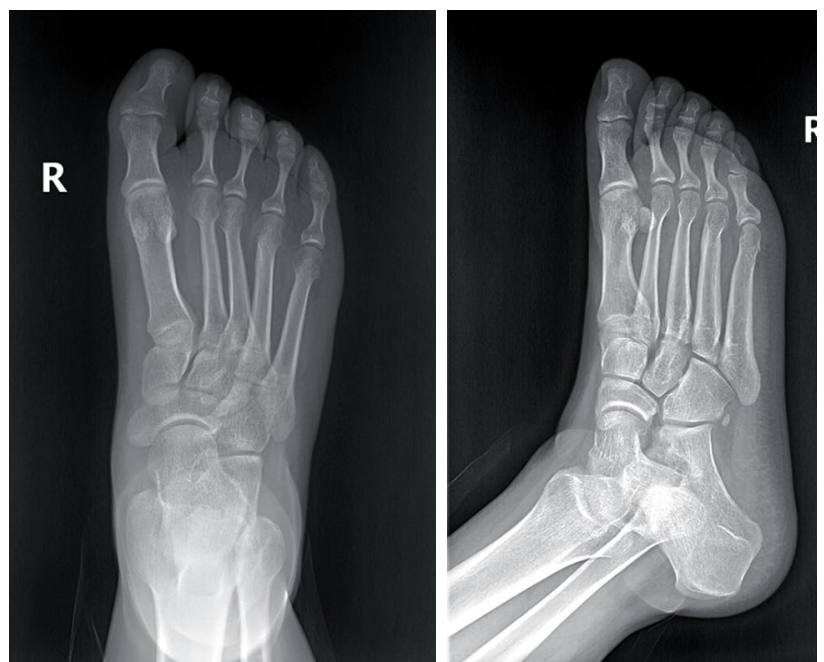

Figure 5. Oblique and anteroposterior views of the right foot at $10^{\text {th }}$ weeks of follow-up. 
The patient was informed that data from the case would be submitted for publication and gave his consent.

\section{DISCUSSION}

Stress fractures are more common in military personnel and athletes, particularly in the lower extremity. ${ }^{[2,3]}$ Although many factors contribute to the formation of metatarsal stress fractures, increased activity is the main factor. ${ }^{[3]}$ Although our patient was not a military personnel or an athlete, as a surgical resident in a tertiary referral hospital, he was a candidate for stress fracture due to reasons such as long working hours, the large volume of the hospital, and the excessive working hours.

Systemic corticosteroids have negative effects on bone metabolism, such as depending on the dose and duration used, increased bone resorption decreased renal and intestinal uptake of calcium, secondary osteoporosis, and avascular necrosis of bone. ${ }^{[5]}$ According to the studies in the literature, the relationship between oral corticosteroid use and the risk of fracture formation is known. ${ }^{[6]}$ In this case, similar to the literature, the side effects of the systemic corticosteroid treatment he received in the treatment of COVID-19 were also thought to be effective in the process.

Cohen et al. ${ }^{[7]}$ found that trunk fat was associated with poor bone quality, reduced trabecular bone volume, reduced stiffness, greater cortical porosity, and reduced bone formation in premenopausal women with normal bone mineral density. In a study by Knapik et al. ${ }^{[8]}$ investigating the relationship between a stress fracture and BMI in combat-trained recruits, female recruits had an increased risk of stress fracture with a low-fat ratio, while a bimodal distribution of stress fracture risk was found in male recruits with both low and high-fat content. In this case, an increase in BMI was observed in our patient after steroid use, which is thought to be related to the stress fracture. In addition, we believe that the patient's flexible pes planus causes abnormal load transfer secondary to the increasing weight gain and contributes to the existing pathology.

Another important factor may be nutritional status. ${ }^{\left[{ }^{9]}\right.}$ However, the effect of vitamin $\mathrm{D}$ and calcium on stress fractures has not been determined. ${ }^{[9]}$ Several studies have suggested that there is a compatibility between a stress fracture and calcium and vitamin $\mathrm{D}$, and the amount of calcium and vitamin D varies depending on age, sex, and exercise intensity, and daily supplementation of 500 to $2,000 \mathrm{mg}$ of calcium and 800 to $2,000 \mathrm{IU}$ of vitamin D would reduce stress fractures. ${ }^{[10]}$ In our patient, serum calcium level was $8.2 \mathrm{mg} / \mathrm{dL}$ and $25-\mathrm{OH}$ vitamin D level was $25 \mathrm{ng} / \mathrm{mL}$, and there was no nutritional disorder.

In conclusion, thousands of individuals have been hospitalized recently due to the COVID-19 pandemic and systemic steroids have been used in their treatment regimens. Considering the secondary effects of systemic steroids on hormonal balance, body structure, BMI, and bone structure/turnover, we believe that these drugs should be given in the lowest possible doses and the shortest treatment periods, if they need to be used. During the pandemic, possible muscle/tendon, and bone pathologies and stress fractures secondary to systemic corticosteroid use and increased BMI should be kept in mind, while evaluating the complaints of patients who have had COVID-19 and have a history of systemic steroid use in daily orthopedic practice, considering the side effects of steroids on the musculoskeletal system.

\section{Declaration of conflicting interests}

The authors declared no conflicts of interest with respect to the authorship and/or publication of this article.

\section{Funding}

The authors received no financial support for the research and/or authorship of this article.

\section{REFERENCES}

1. Milgrom C, Giladi M, Stein M, Kashtan H, Margulies JY, Chisin $\mathrm{R}$, et al. Stress fractures in military recruits. A prospective study showing an unusually high incidence. J Bone Joint Surg $[\mathrm{Br}]$ 1985;67:732-5.

2. Wentz L, Liu PY, Haymes E, Ilich JZ. Females have a greater incidence of stress fractures than males in both military and athletic populations: A systemic review. Mil Med 2011;176:420-30.

3. Warden SJ, Burr DB, Brukner PD. Stress fractures: Pathophysiology, epidemiology, and risk factors. Curr Osteoporos Rep 2006;4:103-9.

4. Chen RC, Tang XP, Tan SY, Liang BL, Wan ZY, Fang JQ, et al. Treatment of severe acute respiratory syndrome with glucosteroids: The Guangzhou experience. Chest 2006;129:1441-52.

5. Mitra R. Adverse effects of corticosteroids on bone metabolism: A review. PM R 2011;3:466-71.

6. Van Staa TP, Leufkens HG, Abenhaim L, Zhang B, Cooper C. Use of oral corticosteroids and risk of fractures. J Bone Miner Res 2000;15:993-1000.

7. Cohen A, Dempster DW, Recker RR, Lappe JM, Zhou H, Zwahlen A, et al. Abdominal fat is associated with lower bone formation and inferior bone quality in healthy premenopausal women: A transiliac bone biopsy study. J Clin Endocrinol Metab 2013;98:2562-72.

8. Knapik JJ, Sharp MA, Montain SJ. Association between stress fracture incidence and predicted body fat in United States Army Basic Combat Training recruits. BMC Musculoskelet Disord 2018;19:161.

9. Bennell K, Matheson G, Meeuwisse W, Brukner P. Risk factors for stress fractures. Sports Med 1999;28:91-122.

10. McCabe MP, Smyth MP, Richardson DR. Current concept review: Vitamin D and stress fractures. Foot Ankle Int 2012;33:526-33. 